\title{
US Naval Facilities Engineering Service Center Environmental Program on Climate Change
}

\author{
Kathleen Paulson \\ Naval Facilities Engineering Service Center, Port Hueneme, CA \\ Dallas Meggitt \\ Sound \& Sea Technology, Inc., Ventura, CA
}

\begin{abstract}
The United States Navy has a long record of responsible environmental stewardship covering many areas such as environmental planning, regulatory compliance, site clean-up, and protection of natural resources. The Navy is now beginning to appreciate the potentially devastating potential of a new set of environmental issues related to climate change. There is a growing recognition that the Navy will need to perform its national security mission in a changing global environment characterized by:
\end{abstract}

- $\quad$ Rising sea levels that threaten the viability of Navy coastal installations

- Increasing extreme weather events that threaten Navy shore installations and air and sea operations

- Climatic shifts in temperature and precipitation with attendant problems such as disruption in water resources, reductions in food supply, and increase in disease vectors

This paper provides a broad overview of climate change-related technology work at the Naval Facilities Engineering Service Center (NAVFAC ESC) in Port Hueneme, California. NAVFAC ESC categorized technologies that can be applied to climate change as mitigation, adaptation, and intervention. An essential element of the Navy's response to climate change is assessment of the potential impacts on Navy infrastructure. Adaptation technologies primarily focus on infrastructure changes to accommodate future climate conditions, including relocating facilities. Mitigation technologies seek to reduce greenhouse gas emissions that are driving climate change, typically through energy conservation or adoption of alternative energy sources. NAVFAC ESC has also identified approaches for intervention technologies that seek to alter the impacts of climate change through such means as carbon sequestration and storm abatement.

\section{Introduction}

The seagoing services and the U. S. Navy in particular, are the services most likely to be adversely affected by sea level rise, inundation from more extreme storm events and other consequences of climate change. The Navy owns extensive (and expensive!) waterside infrastructure and inland buildings and other facilities that may be vulnerable to these changes. As with other organizations with similar potential vulnerabilities, the Navy is beginning to take a proactive approach to understanding the potential issues and to develop methodologies and technologies to deal with them.

For Navy facility managers at the Naval Facilities Engineering Command (NAVFAC), sea level rise (SLR) and increased risk of storm inundation likely is of paramount importance, since most bases are located adjacent to or on waterways, placing both the infrastructure and workforce at risk. Significant areas of certain Navy bases could become inundated during normal operations if the predicted high end of SLR occurs. Other facilities will be at increased jeopardy from inundation and wind due to predicted increases in extreme weather events. The Navy is beginning to develop risk assessment methods reflecting climate change science, site vulnerability and mission criticality.

The work underway at NAVFAC ESC can be categorized as Assessment, Adaptation, Mitigation, and Intervention.

\section{Assessment}

The Navy owns over 500 piers and wharfs. When the Navy builds piers, wharfs and quay walls, they typically are designed to last 50 years and existing structures are generally repaired and refurbished to last up to another 25 to 50 years. Certain regions of the world might experience as much as three meters of change with combined land subsidence and sea level rise. As a result, waterside facilities may become unusable.

Basic infrastructure facilities such as water and wastewater treatment plants are likely to be impacted, since the US Navy: 
- Relies on approximately 171 public water systems

- Owns/operates 59 domestic sewage treatment systems and 38 industrial wastewater treatment systems

- Manages approximately 365 storm water systems such as infiltration systems, ponds, constructed wetlands, etc.

- Manages nearly 1,600 small scale treatment systems such as septic systems, oil water separators, grease traps, etc.

A critical element in developing any strategy or methodology for response to climate change impacts is an objective, defensible means of assessing the impacts. NAVFAC ESC employs several initiatives to adapt or where appropriate, develop, methodologies for assessing potential climate change impacts specific to Navy facilities and interests. The Navy's primary initial effort has been to assess potential inundation due to both SLR and SLR combined with storm surges due to increased extreme weather events.

The Federal Emergency Management Agency (FEMA), the National Oceanic and Atmospheric Administration (NOAA) and other agencies have developed models for predictions of storm surge inundation. NAVFAC ESC is extending these previously developed methodologies to predict possible inundation at Navy facilities from SLR and combined effects with extreme weather events, with the primary objective of providing facilities planners a means for determining which elements of infrastructure are most at risk. Figs. 1-3 demonstrate this kind of assessment analysis using the Navy base at Pearl Harbor, Hawaii as an example. Fig. 1 shows an aerial view of the primary facilities at Pearl Harbor. Fig. 2 emphasizes, in green, the critical infrastructure items at the Pearl Harbor complex. Fig. 3 shows the projected inundation from a combined 3foot SLR and a 4-foot surge from a 500-year storm event, with the impacted infrastructure shown in red. It is immediately clear from this analysis that substantial portions of critical infrastructure at the base are at risk from both sea level rise and the significantly increased inundation due to the combined sea level rise and storm surge. These analyses are used to inform facility planners of the potential risks to allow for planning for mitigation measures.

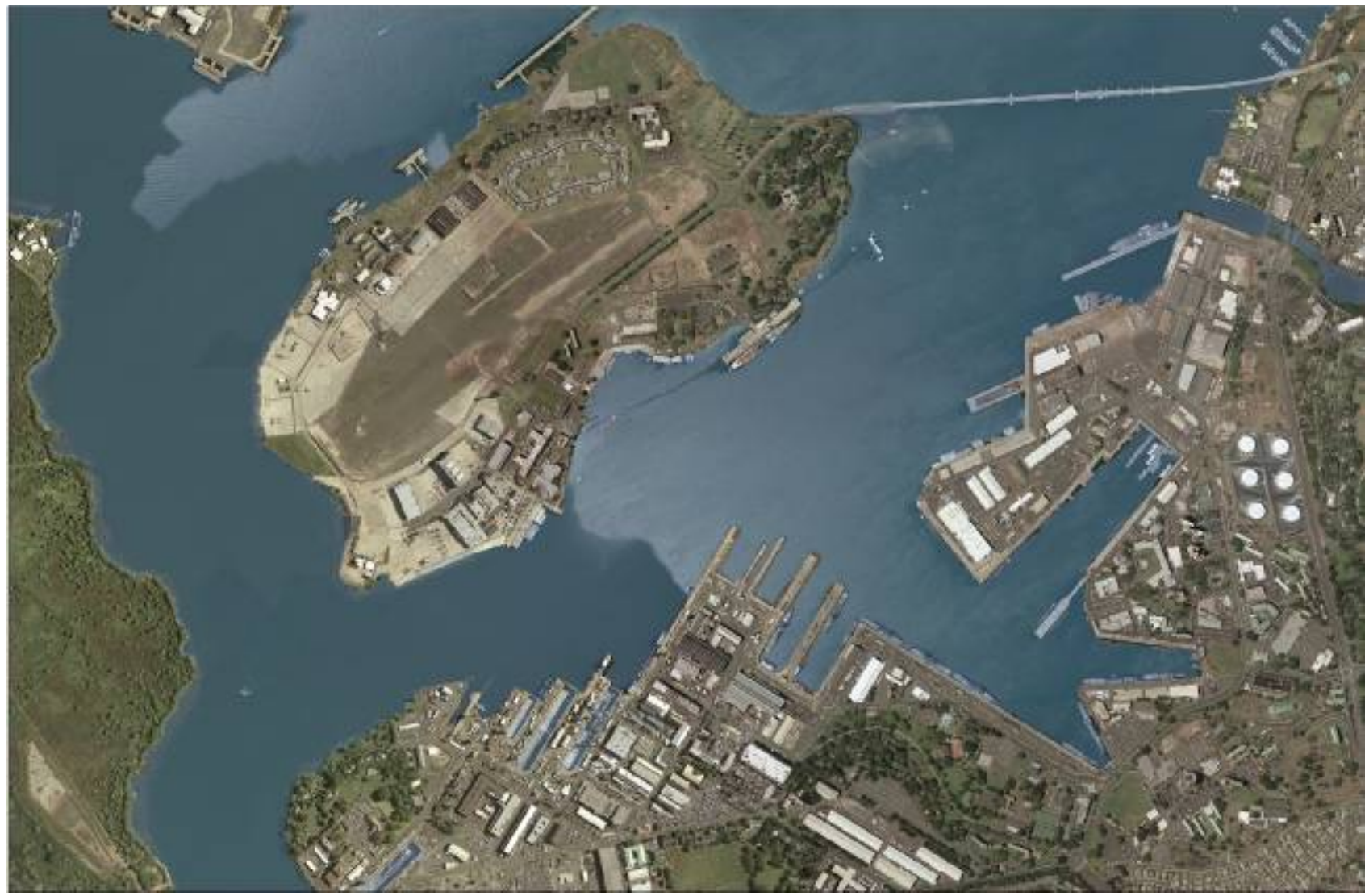

Fig. 1 Navy Base, Pearl Harbor Hawaii (Courtesy USGS) 


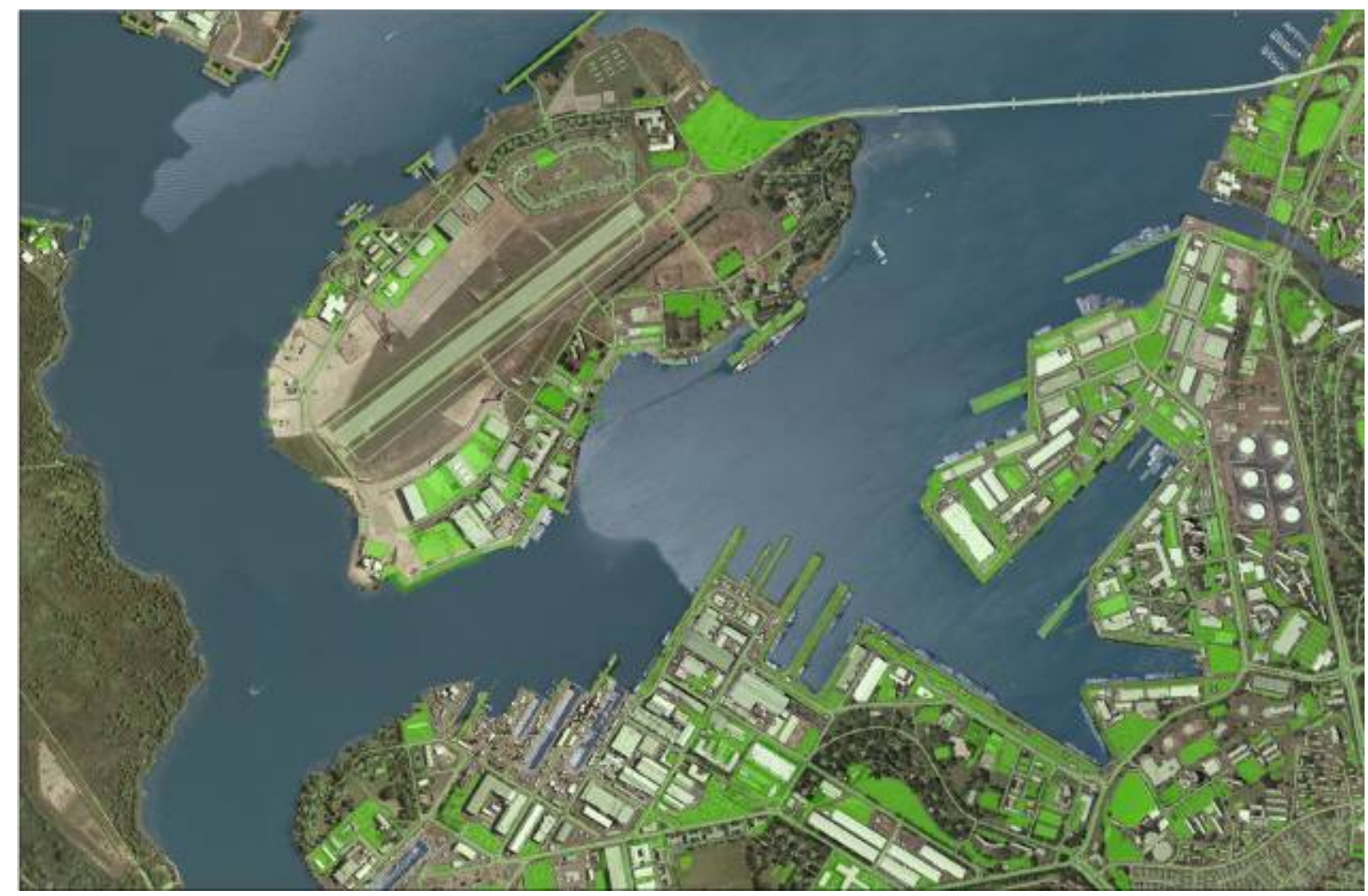

Fig. 2 Key Infrastructure Facilities at Pearl Harbor Complex (Courtesy USGS)

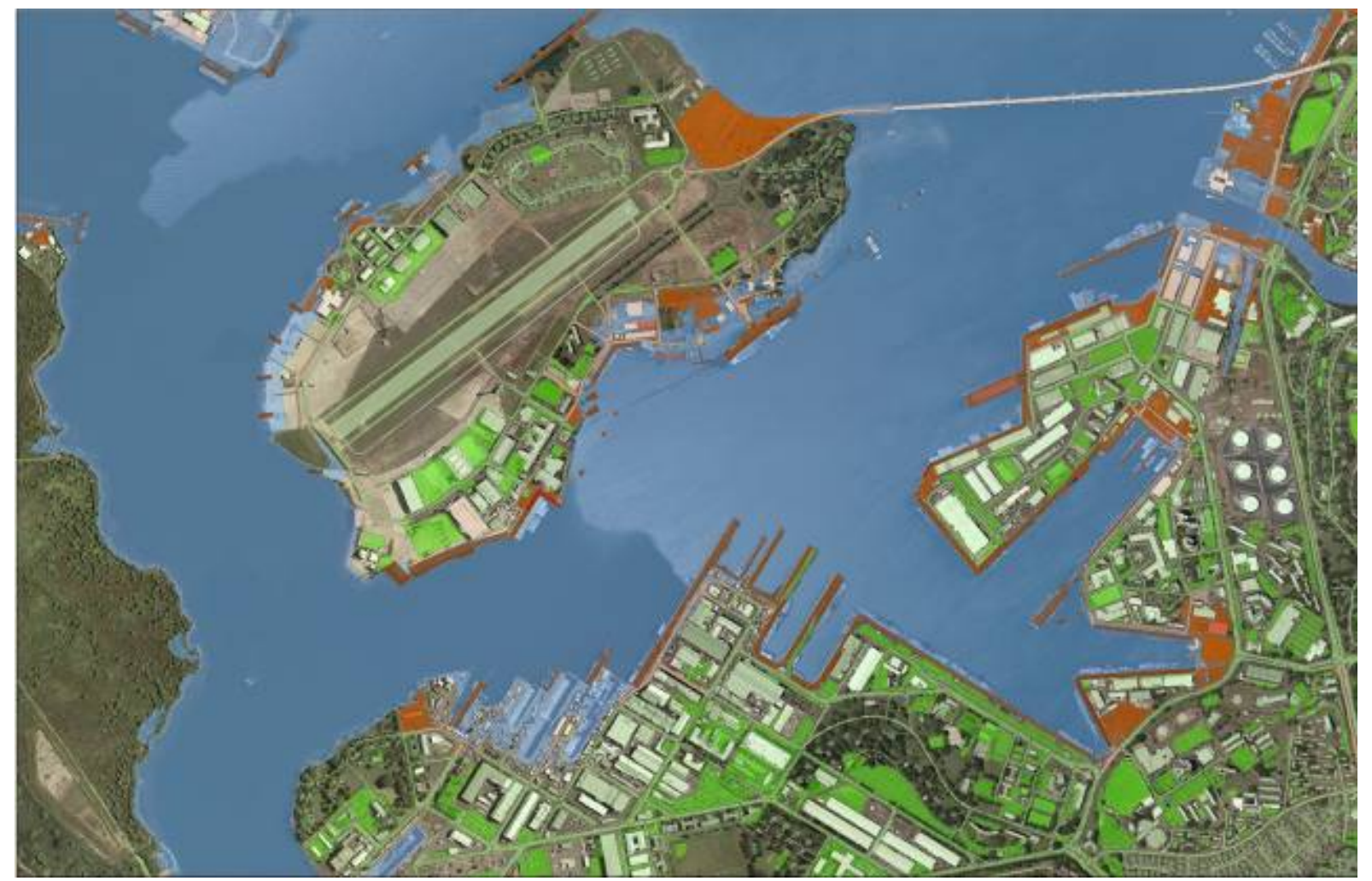

Fig. 3 Projected Inundation from Combined 500-year Storm and 3 foot Sea level Rise (in red) (Courtesy USGS) 


\section{Adaptation}

As a largely waterfront enterprise, the Navy is developing numerous approaches for adapting to sea level rise and the likelihood of more frequent storm surge events. As the use of assessment tools become incorporated into the Navy facility planning processes, facility planners can incorporate into their designs the likely environment, and changes in it, over the life of the facility, which is commonly 50-75 years. This applies to renovation and rehabilitation of existing facilities as well, to extend their useful lives in the face of changing sea level and storm surge risks.

The simplest adaptation strategy in concept, but probably most expensive in implementation, is relocation of critical Navy facilities. This approach is likely limited by availability of suitable sites and cost. However, as part of the enterprisewide facilities planning and development process, it may be more cost effective to selectively relocate functions and facilities than to attempt to protect them in place. In some instances, it may be more cost effective to provide physical protection in the form of berms or levees. In other situations, simply relocating specific equipment (backup communications, power, etc.) from lower floors to higher floors might be effective in helping to ensure continuity of operations. Building designs that raise the habitable levels, for example by incorporating parking structure as the first one or two floors instead of putting them below grade, may be a cost-effective solution. The assessment tools described above provide a means for objective evaluation of these approaches.

Another approach suitable for waterfront facilities such as piers and wharfs is to use floating facilities, based, for example, on the Mobile Offshore Basing (MOB) program sponsored by the Office of Naval Research. The MOB program assessed the practicality and cost of very large floating structures based on offshore oil platform technology for supporting advanced Navy bases. The program concluded that such structures were both practical and highly survivable in extreme conditions. Smaller versions of the MOB concept can be used as piers and wharfs that accommodate sea level rise. Fig. 4 shows one such concept, the Modular Hybrid Floating Pier, being investigated by NAVFAC ESC.

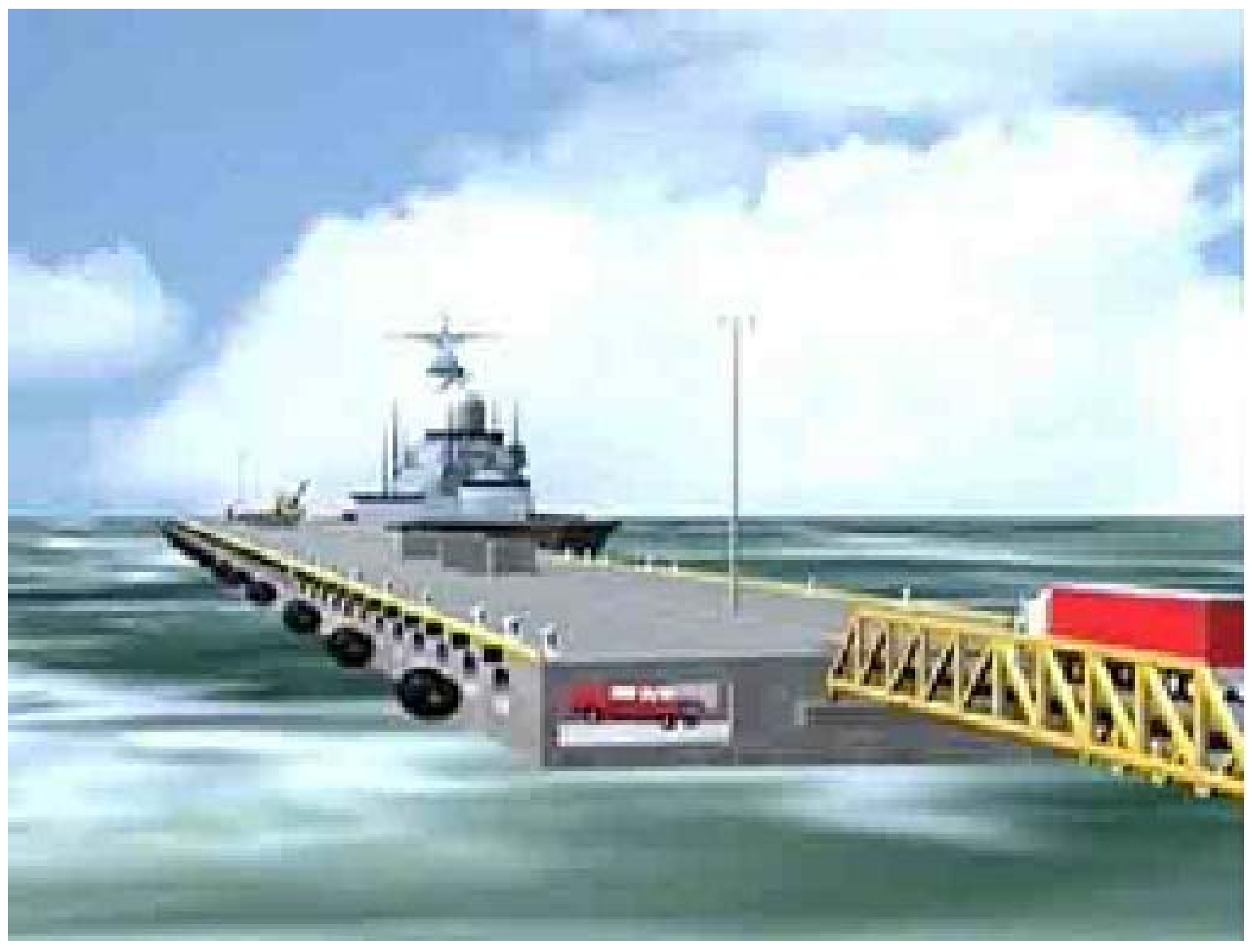

Fig. 4 Modular Hybrid Floating Pier 


\section{Mitigation}

NAVFAC ESC is investigating several Navy-specific mitigation strategies and others that have more general application. As with many organizations, the Navy is seeking technologies that can reduce the carbon footprint of Navy operations. As one of the largest operators of ships and aircraft, the Navy uses large amounts of fossil fuels. The mitigation strategies investigated often have the added benefit of more fuel-efficient operation and, in particular, reduction of fossil fuel usage. Some programs are aimed at near-term results, while others are longer term.

Some of these programs include:

- Conservation: Conservation is generally acknowledged as the least expensive mitigation strategy with the most immediate payoff. The Navy has a long-standing program to investigate and implement methodologies and technologies to conserve energy throughout the enterprise, including building design, construction techniques and facilities operations.

- $\quad$ Bio-Fuels: These include such technologies as methane generation from bio-solids (including algae) and waste-to-power. NAVFAC ESC is evaluating the use of bio-diesel in heavy construction equipment and other Navy mobile and stationary heavy equipment (such as diesel generators). While these are likely longer-term in their impact on climate change, they are an essential element of a comprehensive strategy.

Renewable Energy: The Navy is supporting several renewable energy developments. These include increased use of onsite renewable energy (such as wind, kinetic hydropower [both wave and tidal] and photovoltaic solar), and managing water systems as energy storage to support the electrical grid. Renewable, alternate energy usage is a primary mitigation strategy to reduce fossil fuel usage and greenhouse gas emissions. Using wind, ocean and solar energy on existing and new buildings and designing buildings as "resource islands" is an existing program, along with a recent push for Green Building Council Leadership in Environmental and Energy Design (LEED) certification in new and existing buildings. NAVFAC ESC is supporting several ocean renewable energy projects, including a wave energy buoy that utilizes a linear generator, kinetic hydropower tidal energy turbine development and demonstration, and a wave energy buoy using a mechanical power converter. These are shown in Fig. 5.
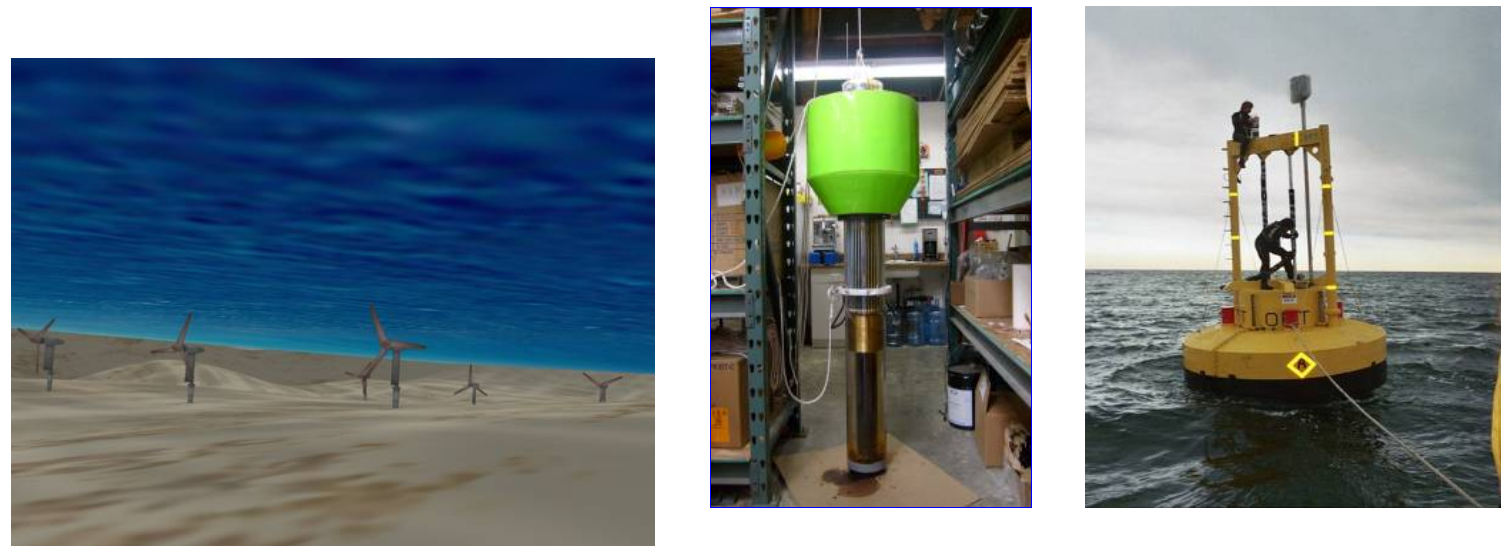

Fig. 5 NAVFAC ESC Renewable Ocean Energy Partnering Projects (Underwater Turbines courtesy of Verdant Power)

Hybrid Vehicles: NAVFAC and the Navy SEABEEs operate a very large amount of construction equipment. NAVFAC ESC is assessing the utilization cycle of medium-duty equipment such as backhoes, front loaders and others to evaluate the utility of hybrid designs to reduce the fossil fuel usage (and thus the carbon footprint) of these machines.

Hydrogen Infrastructure: NAVFAC ESC is evaluating the implications of a hydrogen-based energy infrastructure for Navy operations. In a parallel effort, NAVFAC ESC is evaluating the use of Ocean Thermal Energy Conversion (OTEC) technology to produce hydrogen at the OTEC site. 


\section{Intervention}

Direct intervention strategies that have been proposed include approaches such as sequestering $\mathrm{CO}_{2}$ in subsurface geologic formations and stimulating phytoplankton blooms to sequester atmospheric $\mathrm{CO}_{2}$. Other approaches seek to reduce hurricane intensity by cooling Gulf Coast surface waters. The Navy is evaluating its role in intervention. In some cases $\left(\mathrm{CO}_{2}\right.$ sequestration in undersea formations), Navy technology may have application. In others, Navy engineering expertise may be useful for assessing the strategy. These efforts must be thoroughly evaluated for their practicality and to avoid unintended consequences.

\section{Summary}

The Naval Facilities Engineering Command, and the Naval Facilities Engineering Service Center, have a wide variety of programs underway related to climate change impacts on the Navy and Navy facilities. These include development of tools for facility planners, assessment of adaptation strategies appropriate for the Navy, investigation of short and term mitigation measures suitable for Navy implementation, and evaluation of intervention approaches. 